\title{
Effect of Processing on Ferulic Acid Content in Foxtail Millet (Setaria italica) Grain Cultivars Evaluated by HPTLC
}

\author{
GIRIDHAR GOUDAR and G.J.SATHISHA* \\ Department of Biochemistry, Kuvempu University, Shimoga - 577451, Karnataka, India. \\ *Corresponding author E-mail: satishlec@gmail.com \\ http://dx.doi.org/10.13005/ojc/320458
}

(Received: July 15, 2016; Accepted: August 11, 2016)

\begin{abstract}
ABSTARCT
Foxtail millet (Setaria italica) grain cultivars were analyzed for the phenolic components which have beneficial effects on human health. The aim of the present study was to evaluate the effect of dehusking on total phenolic and total flavonoid contents in four types of foxtail millet grain varieties. These grains were extracted for phenolic compounds and evaluated for total phenolic content (TPC), total flavonoid content (TFC) and antioxidant activity. TPC was analyzed by Folin-Ciocalteu method, TFC by aluminium chloride method and antioxidant activity by 1,1-diphenyl-2-picrylhydrazyl (DPPH) radical scavenging assay. High Performance Thin Layer Chromatography (HPTLC) evaluation was done for ferulic acid in the phenolic extracts, identification was done by comparing $R_{f}$ value of the ferulic acid standard with the sample extracts and quantification was done using the peak areas of the obtained chromatograms. Results revealed that TPC, TFC and antioxidant activity was found to be high in husk of the grains compared to whole grains and dehusked grains, whereas when compared amoung different cultivars Black variety got the high content of phenolics.
\end{abstract}

Keywords: Foxtail millet, phenolic, flavonoid, ferulic acid, HPTLC.

\section{INTRODUCTION}

Millet grain phenolics possess bioactivities against several pathophysiological conditions and may serve as potential natural sources of antioxidants in food and biological systems ${ }^{1}$. They are the cereal crops with small sized seeds which belongs to family Poaceae. They are superior to rice and wheat, and therefore provide protein, mineral, and vitamins to the poor where the need for such nutrients is in high demand ${ }^{2}$. Foxtail millet (Setaria italica) is one of the oldest cultivated millet crops and is often cultivated in harsh conditions as an alternative to maize because of their better adaptability to arid and barren lands than most other crops $^{3}$.

Polyphenols are of current interest due to their important biological properties such as improved gut health and reduced risk of coronary heart disease $e^{4,5}$, anti-inflammatory ${ }^{6}$. antimutagenic, 
anticarcinogenic and antioxidant activities ${ }^{7,8}$. Whole grains contain unique phytochemicals that complement those in fruits and vegetables when consumed together. For instance, various classes of phenolic compounds in grains include phenolic acids, anthocyanidins, quinones, flavonols, chalcones, flavones, flavanones, and amino phenolic compounds ${ }^{9-11}$. It is generally believed that antioxidants scavenge free radicals and reactive oxygen species and thus inhibit oxidative mechanisms which lead to degenerative disease ${ }^{12}$. An increasing number of epidemiological studies have shown an inverse correlation between the consumption of dietary antioxidants and incidence of various diseases including cancer and heart disease ${ }^{13}$.

Ferulic acid, the most abundant phenolic acid in cereal grains ${ }^{14}$. Grain fractions with enhanced levels of ferulic acid are of great interest to both researchers and the food industry for use as functional food ingredients ${ }^{15}$ because of their health benefits to humans. Ferulic acid is attached into wall matrices to structural polysaccharides via ester linkage with its carboxylic group. In grasses, Poaceae family, it is linked to the acid group acylating the primary hydroxyl at the C-5 position of $\alpha$-L-arabinofuranosyl residues ${ }^{16}$.

The health benefits of millets are dependent upon their metabolic profiles, including the types and amounts of natural phenolic compounds present. Further studies on these phenolic compounds would enhance understanding of the biological activity of millet phenolics and their benefits to human health. Generally millet grains are subjected to domestic processing such as dehusking before they are consumed. Investigation on effect of domestic processing on individual phenolic profile in foxtail millet is scarce. The present study aims on the effect of dehusking on the phenolic content and evaluation of ferulic acid content in foxtail millet varieties utilizing High Performance Thin Layer Chromatography (HPTLC).

\section{MATERIALS AND METHODS}

\section{Grain samples}

The foxtail millet grain varieties (HMT1-100, PSC-4, Sia-3126 \& black) were procured from University of Agricultural Sciences, Dharwad, Karnataka for the study.

\section{Chemicals}

Analytical grade reagent chemicals aluminium chloride, ethyl acetate, ethyl alcohol, hydrochloric acid, methanol, sodium hydroxide, sodium nitrite, sodium sulphate and sodium carbonate of analytical grade were procured from Thomas Baker Chemicals (Mumbai, India). Folin-Ciocalteu reagent was procured from Merck KGaA, (Darmstadt, Germany). Gallic acid, ferulic acid, butylated hydroxy anisole (BHA), butylated hydroxy toluene (BHT), rutin and 2,2'-diphenyl-1picrylhydrazyl (DPPH) were purchased from SigmaAldrich Co. (St.Louis, USA).

\section{Extraction of phenolic compounds}

Phenolic components were isolated according to the method ${ }^{17}$. Flours of the grain samples were extracted using $70 \%$ ethanol (4 x 50 $\mathrm{mL}, 3 \mathrm{~h}$ each) with agitation; the supernatants were obtained by centrifugation at $15,000 \mathrm{rpm}$ for $15 \mathrm{~min}$ at $4^{\circ} \mathrm{C}$ (Sigma $3 \mathrm{~K} 30$, Germany) and concentrated under vacuum with rotary evaporator at $50^{\circ} \mathrm{C}, 45$ rpm (Hahnvapor, Hahnshin Scientific Co., Korea) and the $\mathrm{pH}$ was adjusted to 2.00 with $4 \mathrm{M} \mathrm{HCl}$. Phenolic compounds were separated by ethyl acetate phase separation ( $4 \times 50 \mathrm{~mL}$ ), and the pooled fractions were treated with anhydrous sodium sulphate to remove moisture; filtered, and evaporated to dryness. Phenolic compounds redissolved in methanol $(1 \mathrm{ml})$ and stored at $-20^{\circ} \mathrm{C}$ till further analysis. A study stated that the combination of enzymatic or chemical methods with physical pretreatments can substantially increase the extraction efficiency, especially regarding lignocellulosic matrices. The goal of pre-treatment technology is to alter or remove structural and compositional impediments to hydrolysis ${ }^{18}$. Phenolic substances have a higher affinity with polar solvents, such as ethanol ${ }^{19,20}$. hence various solvent systems are used for optimization of extraction process of phenolic compounds. Also, the levels of total constituents in plant derivates depend on the extraction process and its variables, such as the solvent used ${ }^{21}$.

\section{Determination of total phenolic content (TPC)} TPC was determined by the method described by ${ }^{22}$. Briefly, the appropriate dilutions 
of extracts were reacted with the Folin-Ciocalteu reagent and the reaction was neutralized with sodium carbonate. The absorbance was measured at 765 $\mathrm{nm}$ after 60 minutes incubation at room temperature under dark using UV-Visible Spectrophotometer (Cary 50, Varian, Middelburg, Netherlands). Gallic acid was used as reference standard, and TPC of the samples were expressed as $\mu \mathrm{g}$ of gallic acid equivalent per gm ( $\mu \mathrm{g} \mathrm{GAE} / \mathrm{g}$ ) of sample on dry basis.<smiles>COc1cc(/C=C/C(=O)O)ccc1O</smiles>

Fig. 1: Ferulic acid

Table 1: TPC of foxtail millet cultivars

\begin{tabular}{lccc}
\hline Variety & \multicolumn{3}{c}{ TPC $\left({ }^{*} \mu g\right.$ GAE/g) } \\
& $\begin{array}{c}\text { Whole } \\
\text { Dehusked } \\
\text { grain }\end{array}$ & grain & \\
& & & \\
\hline HMT-1-100 & 527.5 & 357.5 & 810.2 \\
PSC-4 & 440.1 & 272.2 & 547.6 \\
Sia-3126 & 420.0 & 240.3 & 552.8 \\
Black & 982.8 & 505.3 & 1140.3 \\
\hline
\end{tabular}

*GAE: gallic acid equivalent; All values are mean of three replicate experiments

Table 2: TFC of foxtail millet cultivars

\begin{tabular}{lccc}
\hline Variety & \multicolumn{3}{c}{ TFC ${ }^{*}{ }^{*} \mu \mathrm{g}$ RE/g) } \\
& $\begin{array}{c}\text { Whole } \\
\text { grain }\end{array}$ & $\begin{array}{c}\text { Dehusked } \\
\text { grain }\end{array}$ & Husk \\
& & 322.2 & 515.2 \\
HMT-1-100 & 385.4 & 240.7 & 372.8 \\
PSC-4 & 290.5 & 230.1 & 352.4 \\
Sia-3126 & 282.5 & 432.4 & 840.2 \\
Black & 590.3 & & \\
\hline
\end{tabular}

${ }^{\star} \mathrm{RE}$ : rutin equivalent; All values are mean of three replicate experiments
Determination of total flavonoid content (TFC)

TFC was determined by aluminium chloride colorimetric method ${ }^{23}$ with minor modification explained by ${ }^{17}$. In brief, aliquots $(1 \mathrm{ml})$ of appropriately diluted extracts or standard solutions were pipette into $15 \mathrm{ml}$ polypropylene conical tubes containing $2 \mathrm{ml}$ double distilled $\mathrm{H}_{2} \mathrm{O}$ and mixed with $0.15 \mathrm{ml}$ of $5 \% \mathrm{NaNO}_{2}$. After $5 \mathrm{~min}, 0.15 \mathrm{ml}$ of $10 \% \mathrm{AlCl}_{3} \cdot 6 \mathrm{H}_{2} \mathrm{O}$ solution was added and the mixture was allowed to stand for another $5 \mathrm{~min}$, and then $1 \mathrm{ml}$ of $1 \mathrm{M} \mathrm{NaOH}$ was added. The reaction solution was well mixed, incubated at room temperature for $15 \mathrm{~min}$ and the absorbance was determined at $415 \mathrm{~nm}$ using the UV-Visible Spectrophotometer (Cary 50, Varian, Middelburg, Netherlands). Rutin was used as reference standard, and TFC of the samples were expressed as $\mu \mathrm{g}$ of rutin equivalent per gm ( $\mu \mathrm{g} \mathrm{RE} / \mathrm{g})$ of sample on dry basis.

\section{Antioxidant activity by free radical-scavenging scavenging assay (DPPH method)}

Free radical-scavenging capacity (DPPH) of phenolic acid extracts in foxtail millet cultivars were estimated according to the previously reported procedure using the DPPH radical ${ }^{24}$. In brief, an aliquot $(1 \mathrm{~mL})$ of phenolic extracts were mixed with the freshly prepared $1 \mathrm{~mL}$ of $(200 \mu \mathrm{M}) \mathrm{DPPH}$ in ethanol. The control contained all the reagents except phenolic extracts. The mixture was shaken vigorously and left to stand for $20 \mathrm{~min}$ at room temperature in the dark. The absorbance of the resulting solution was measured using UV-Visible spectrophotometer (Cary 50, Varian, Middelburg, Netherlands) at $517 \mathrm{~nm}$. Absorbance data were collected and transformed

Table 3: Antioxidant activity of foxtail millet cultivars

\begin{tabular}{|c|c|c|c|}
\hline \multirow[t]{2}{*}{ Variety } & \multicolumn{3}{|c|}{ DPPH assay (I\%) } \\
\hline & $\begin{array}{l}\text { Whole } \\
\text { grain }\end{array}$ & $\begin{array}{c}\text { Dehusked } \\
\text { grain }\end{array}$ & Husk \\
\hline НМТ-1-100 & 56.58 & 45.53 & 67.52 \\
\hline PSC-4 & 55.24 & 42.96 & 61.38 \\
\hline Sia-3126 & 53.90 & 41.96 & 60.71 \\
\hline Black & 69.41 & 64.17 & 79.24 \\
\hline
\end{tabular}

All values are mean of three replicate experiments 
to radical scavenging activity ( $1 \%$ ) according to equation:

$$
1 \%=(\text { Ac-As }) \times 100 / A c
$$

where 'Ac' is the absorbance of control (without extract) and 'As' is the absorbance of sample. Synthetic antioxidants such as BHA and BHT were used for comparison

\section{HPTLC conditions \& analysis}

HPTLC analysis was performed on precoated silica gel $60 \mathrm{~F}_{254}$ aluminium back HPTLC plates (Merck, Darmstadt, Germany) of size $20 \times 10 \mathrm{~cm}$. The standard solution of ferulic acid and sample extracts were applied onto the plates of $8 \mathrm{~mm}$ length with automatic sample applicator (Linomat V, CAMAG, Switzerland) with the aid of Hamilton syringe $(10 \mu \mathrm{L})$. Development of the plate was done at room temperature $\left(27 \pm 2^{\circ} \mathrm{C}\right)$ in the vertical glass twin-trough glass chamber $(20 \mathrm{~cm} \times 10 \mathrm{~cm}$, with metal lids; CAMAG, Switzerland) which was previously saturated with mobile phase $(20 \mathrm{~mL})$ for 20 minutes. Mobile phase was composed of solvents toluene, ethyl acetate, formic acid and methanol in the ratio $6: 6: 1: 0.4(\mathrm{v} / \mathrm{v})$. The plate was developed up to a distance of about $75 \mathrm{~mm}$ and were air-dried

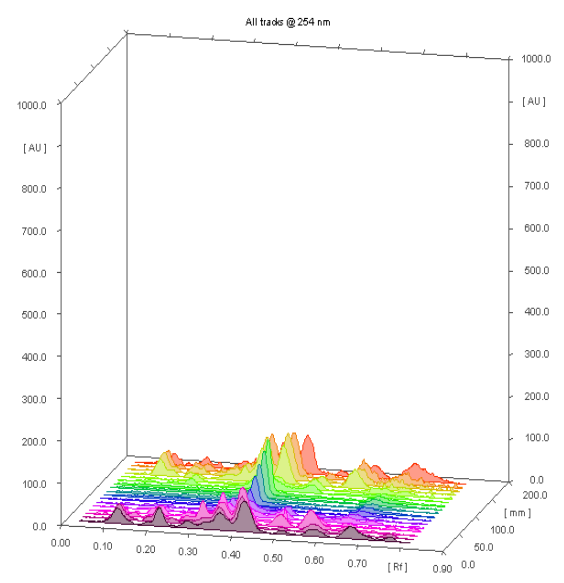

at room temperature for $20 \mathrm{~min}$ and then heated at $105 \pm 2^{\circ} \mathrm{C}$ for 5 minutes in hot air oven. The plates were observed for the compact bands inside UV cabinet (CAMAG, Switzerland) and the TLC images were captured at $254 \mathrm{~nm}$. Scanning was performed in TLC Scanner III (CAMAG, Switzerland). Quantitative analysis was performed at wavelength $254 \mathrm{~nm}$ in absorbance mode with win CATS software (Version 1.2.0). The TLC plates were scanned by a CAMAG TLC Scanner III and quantified at their wavelengths of maximum absorption. A deuterium (D2) lamp was used to scan the plates with the remission absorption mode having the slit width $6.0 \times 0.30 \mathrm{~mm}$ (micro). HPTLC chromatogram and photodocumentation of ferulic acid along with phenolic extracts of samples were analyzed at 254nm (Fig.2). The densitograms were further scanned for their in situ UV spectra from 200 to $700 \mathrm{~nm}$ and overlaid with the UV absorption spectra of phenolic acid standard in all the sample extracts.

\section{RESULTS AND DISCUSSIONS}

The present study was aimed to assess the effect of processing (dehulling) on the phenolic compounds and antioxidant properties in the foxtail millet cultivars.

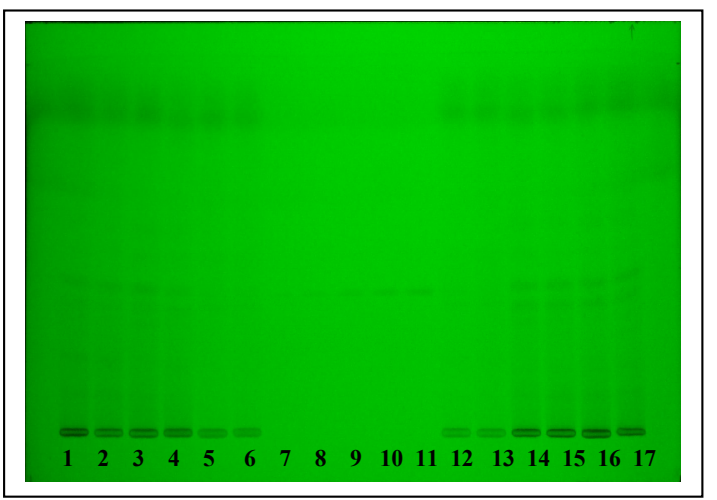

Track 1-4: foxtail millet whole grain extracts; Track 1: HMT-1-100, Track 2: PSC-4, Track 3: Sia-3126, Track 4: Black, Track 5 \& 6: foxtail millet dehusked grain extracts; Track 5: HMT-1-100, Track 6: PSC-4; Track 7-11: ferulic acid standard (100ng300ng); Track 12 \& 13: foxtail millet dehusked grain extracts; Track 12: Sia-3126, Track 13: Black, Track 14-17: foxtail millet husk extracts; Track 14: HMT-1-100, Track 15: PSC-4, Track 16: Sia-3126, Track 17: Black

(a) HPTLC chromatogram, (b) HPTLC image profile at 254nm

Fig. 2: HPTLC chromatogram \& image profile 


\section{Phenolic compounds}

TPC and TFC in the analyzed foxtail millet grain cultivars is presented in Table $1 \& 2$. Irrespective of the cultivars TPC and TFC was found in the order; husk > whole grain $>$ dehusked grain. TPC for the whole grains, dehusked grains and husk was ranging from 420.0 to $982.8,240.3$ to 505.3 and 547.6 to $1140.3 \mu \mathrm{g} / \mathrm{g}$ GAE, respectively.
Whereas, TFC was comparatively less than TPC which was ranging from 282.5 to $590.3,230.1$ to 432.4 and 352.4 to $840.2 \mu \mathrm{g} / \mathrm{g}$ RE, respectively for whole grains, dehusked grains and husk samples. When compared amoung the cultivars the black variety got the highest TPC i.e., 982.8, 505.3 and $1140.3 \mu \mathrm{g} / \mathrm{g}$ GAE and TFC i.e., 590.3, 432.4 and $840.2 \mu \mathrm{g} / \mathrm{g}$ RE for whole grain, dehusked and husk

Ferulic acid on all Tracks
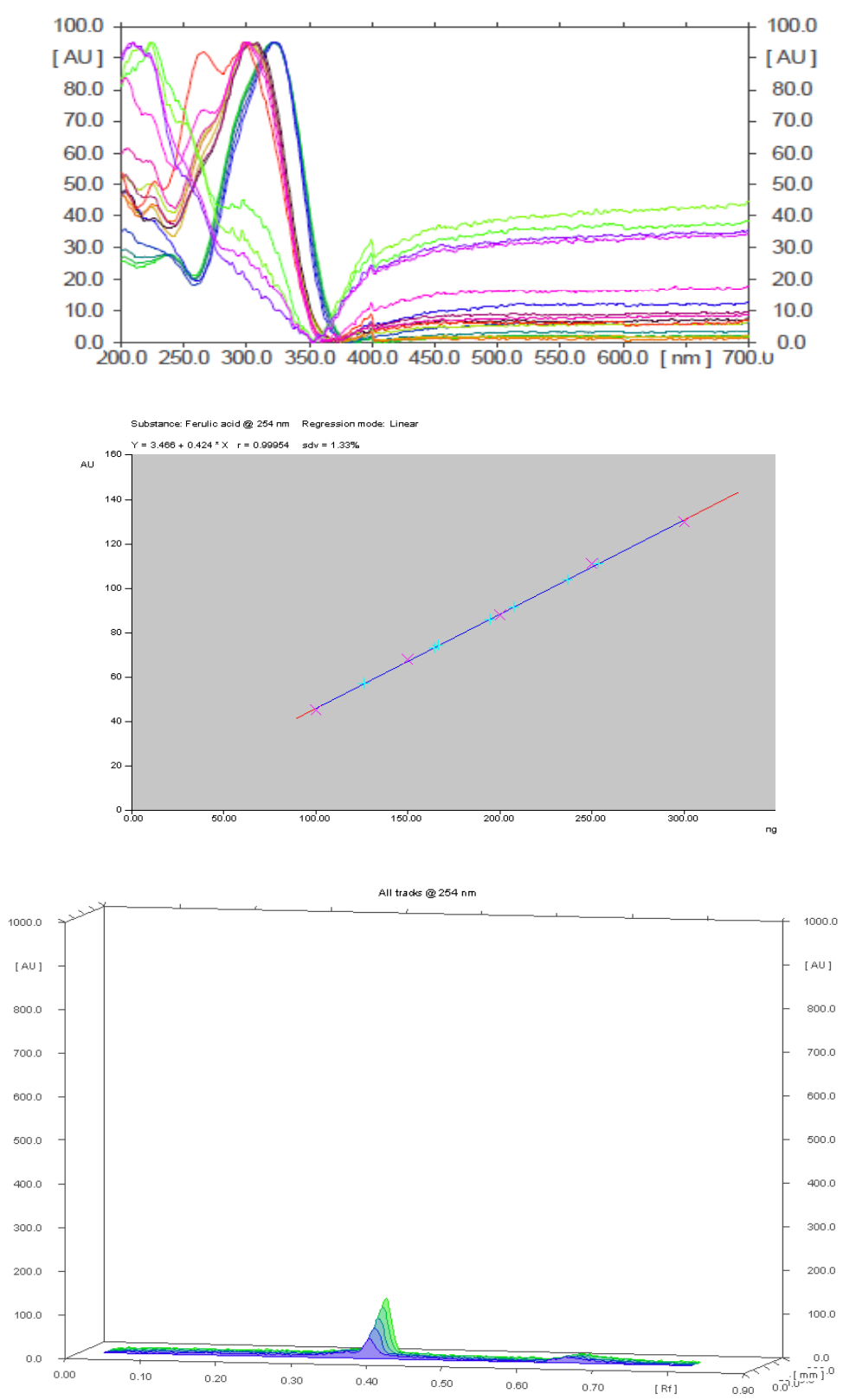

Fig. 3: HPTLC chromatogram \& calibration curve of ferulic acid reference standard 
samples respectively. Hence there was significant difference in the content of TPC and TFC amoung the cultivars as well as for effect of processing (dehulling) in these grains.

\section{Antioxidant property}

The radical scavenging activity of phenolic fraction analyzed in the grain samples is presented in Table 3. It was in the range from 53.90 to 69.41 , 41.96 to 64.17 and 60.71 to 79.24 for whole grains, dehusked grains and husk of the samples respectively, which was presented as $1 \%$ using the above mentioned equation. Amoung the varieties, black variety had the highest antioxidant property i.e., $69.41,64.17$ and 79.24 , whereas Sia-3126 variety had the least antioxidant property i.e., 53.90, 41.96 and 60.71 for whole grains, dehusked and husk samples respectively. Also the antioxidant property was found to be significantly lower than that of synthetic antioxidants such as butylated hydroxyanisole (BHA, 64.88) and butylated hydroxytoluene (BHT, 69.08) for the concentration $10 \mu \mathrm{g} / \mathrm{ml}$.

Similar observations were also made in the case of barley, for which the antioxidant activity of methanolic extracts was found to be lower than that of BHT and gallic acid ${ }^{25}$. Also a similar study on finger millet reported that, it is a potent source of antioxidants and has potent radical-scavenging activity that is higher than that of wheat and rice; these results corresponded to their phenolic content ${ }^{26}$.

\section{HPTLC analysis}

Thin layer chromatography, in particular its high-performance application, is still a widely used analytical technique in analysis of pharmaceuticals, botanicals, foodstuff, environmental and clinical samples ${ }^{27}$. The chromatographic profiles obtained for phenolic fractions in whole grains, dehusked grains and husk samples of the foxtail millet varieties is presented in Fig. 2 (a\&b).

HPLC analytical technique is used by many researchers for the studies for analysis of ferulic acid ${ }^{28-30}$., In one of the study it has been analyzed by traditional TLC method by developing with chloroform-methanol-formic acid (85:15:1) and visualizing the spots at $254 \mathrm{~nm}$ which is ferulic acid absorbance ${ }^{31}$, since the traditional TLC method is done manually and has many disadvantages in quantifying the bioactive compounds. In the present study, a new method i.e., HPTLC which is fast, reliable and accurate for quantification of phenolic compounds is implemented for analyzing ferulic acid. It was analyzed in all the varieties and evaluated for effect of processing (dehusking). Ferulic acid was identified in the sample extracts by comparing the $R_{f}$ values with the reference standard. Quantification of ferulic acid content in the samples was done using the calibration curve obtained with increasing concentrations (100-300 ng) of ferulic acid solution. The results obtained for the whole grain samples was in the sequence Black (284.81 ng) > HMT-1$100(262.81 \mathrm{ng})>$ PSC-4 $(247.81 \mathrm{ng})>$ Sia-3126 (187.46 ng). Whereas for dehusked grain samples the sequence was; Black (125.14 ng) > HMT-1-100 (123.42 ng) > PSC-4 (112.14 ng) > Sia-3126 (94.31 $\mathrm{ng})$. The husk of the grain samples got the high content of ferulic acid compared to whole grain and dehusked grain extracts, which was in the range from 288.90 to $330.00 \mathrm{ng}$; Black (330.00 ng) > HMT-1-100 (319.35 ng) > PSC-4 (304.79 ng) > Sia3126 (288.90 ng). Hence the dark coloured variety i.e., Black has got the highest amount of ferulic acid comparatively with other cultivars. In a study on proso millet, in addition to monomers of ferulic acids, dehydrodiferulates were also reported ${ }^{32}$. Also as per the study of ${ }^{33}$, the results revealed that the content and type of phenolic acids varied depending on the type of millet as well as processing method considered.

Chromatographic profiles obtained for ferulic acid reference standard is presented in Fig. 3. The method was validated for linearity, LOD and LOQ by analyzing reference standard and the analytes. (i) Linearity Range: The linearity range of ferulic acid was obtained by applying a series of spots of different volumes which were applied so as to get 100-300 ng quantity per band, respectively. The plate was scanned, and a curve was prepared with respect to height and area vs. amount per spot.

(ii) $L O D$ and $L O Q: L O D$ and the $L O Q$ were calculated based on the standard deviation (SD) of the response and the slope $(S)$ of the calibration curve at levels approaching the LOD according to the formulae: $[\mathrm{LOD}=3.3(\mathrm{SD} / S)$ and $\mathrm{LOQ}=10(\mathrm{SD} / \mathrm{S})]$. The 
standard deviation of the response was determined based on the standard deviation of $y$-intercepts of regression lines.

\section{CONCLUSION}

The distribution of phenolic compounds in foxtail millet cultivars may have important implications in end-use applications and in generating health benefits as functional foods. The analyzed foxtail millet grain cultivars had a significant difference in the phenolic as well as flavonoid content after and before processing (dehusking). Ferulic acid content, evaluated by HPTLC in the millet grains is a novel attempt for the fast and accurate separation and quantification. Results reveal that ferulic acid quantified in whole grains, dehusked grains and husk had a significant difference within the analyzed varieties and also for processing effect (dehusking). These grains have a potential to be used to prepare convenience food products such as ready to eat (RTE) or ready to cook (RTC), which have a dual role of fulfilling the nutrient requirements and at the same time as functional food in combating several health disorders.

\section{REFERENCES}

1. Shahidi, F.; Chandrasekara, A. J. Funct. Foods. 2013, 5, 570-581.

2. Taylor, J. R. N.; Emmanbux, M. N. 2008. Millets. In A. Arend and F. D. Bello. (Eds.). Handbook of gluten free cereal products and beverage, p.119-148. Amsterdam \& London: Academic Press.

3. Panaud, O. 2006. Foxtail millet. In C.Kole (Ed.). Cereals and millets, p.325-332. Berlin, Heidelberg: Springer Verlag.

4. Fava, F.; Lovegrove, J. A.; Gitau, R.; Jackson, K. G.; Tuohy, K. M. Curr. Med. Chem. 2006, 13, 3005-3021.

5. Romier, B.; Schneider, Y. J.; Larondelle, Y.; During, A. Nutr. Rev. 2009, 67, 363-378.

6. Koshihara, Y.; Neichi, T.; Murota, S.; Lao, A.; Fujimoto, Y.; Tatsuno, T. Biochim. Biophys. Acta. 1984, 792, 92-97.

7. Chandrasekara, A.; Shahidi, F. J. Agric. Food Chem. 2011, 59, 428-436.

8. Serrano, A.; Palacios, C.; Roy, G.; Cespon, C.; Villar, M. L. Arch. Biochem. Biophys. 1998, 350, 49-54.

9. Lloyd, B.J.; Siebenmorgen, T.J.; Beers, K.W. Cereal Chem. 2000, 77, 551-555.

10. Maillard, M.N.; Berset, C. J. Agric. Food Chem. 1995, 43(7), 1789-1793.

11. Thompson, L.U. Cr. Rev. Food Sci.1994, 34, 473-497.

12. Sushama, A. M.; V. Rajalakshmi; Sahayog, N. J.; Arun, S. Food Chem. 2011, Toxicol. 49: 2005-2012.

13. Kris-Etherton, P. M.; Heckar, K. D.; Bonanome,
A.; Coval, S. M.; Binkoski, A. E.; Hilpert, K. F.; Griel, A. E.; Etherton, T. D. Am. J. Med. 2002, 113, 71S-88S.

14. Adom, K. K.; Sorrells, M. E.; Liu, R. H. J. Agric. Food Chem. 2003, 51(26), 7825-7834.

15. Malkki, Y. Acta Aliment. 2004, 33(1), 39-62.

16. Helene, B.; Olivier, R.; Christelle, R.; Michel, P.; Claude, D.; Christophe, B. J. Sci. Food Agric. 2008, 88, 1494-1511.

17. Hemalatha, S.; Giridhar, G. Biotech. Bioinfor. Bioeng. 2012, 2(2), 653-658.

18. Mosier, N.; Wyman, C.; Dale, B.; Elander, R.; Lee, Y.; Holtzaple, M.; Michael, L. Bioresour. Technol. 2005, 96, 673-686.

19. Spagolla, L. C.; Santos, M. M.; Passos, L. M. L.; Aguiar, C. L. Rev. Ciênc. Farm. Básica Aplicada. 2009. 30(2), 187-191.

20. Tiwari, P.; Kumar, B.; Kaur, M.; Kaur, G.; Kaur, H. Int. Pharm. Sci. 2011, 1(1), 98-106.

21. Sideney, B. O.; Zípora, M. Q. S.; Francini, Y. K.; Shaiana, P. M. J. Med. Plants Res. 2015, 9(17), 569-575.

22. Singleton, V. L.; J. A. Rossi. Am. J. Enol. Vitic. 1965, 16, 144-158.

23. Yun, S.; Liang, J.; Peng, X.; Yan, L.; Jinsong, B. J. Cereal Sci. 2009, 49, 106-111.

24. Revanappa, S. B.; Salimath, P. V. J. Food Biochem. 2011, 35, 759-775.

25. Maillard, M. N.; Soum, M. H.; Boivia, P.; Berset, C. Lebensm. Wiss. Technol. 1996, 3, 238-244.

26. Sripriya, G.; Chandrasekharan, K.; Murty, V.S.; Chandra, T.S. Food Chem. 1996, 57, 
537-540.

27. Renger, B.; Végh, Z.; Ferenczi-Fodor, K. J. Chromatogr. A. 2011, 1218(19), 2712-2721.

28. Pussayanawin, V.; Wetzel, D. J. Chromatogr. A. 1987, 391, 243-255.

29. Sen, A.; Miller, S.; Arnason, J.; Fulcher, R. Phytochem. Anal. 1991, 2, 225-229.
30. Waldron, K.; Parr, A.; Ng, A.; Ralph, J. J. Sci. Food Agric. 1996, 7, 305-312.

31. Mabinya, L.; Mafunga, T.; Brand, J. Afr. J. Biotechnol. 2006, 5, 1271-1273.

32. Mattila, P.; Pihlava, J. M.; Hellstrom, J. J. Agric. Food Chem. 2005, 53, 8290-8295.

33. Pradeep, P. M.; Sreerama, Y. N. Food Chem. 2015, 169, 455-463. 